\title{
Electrospun polyester-urethane scaffold preserves mechanical properties and exhibits strain stiffening during in situ tissue ingrowth and degradation
}

\author{
Hugo Krynauw ${ }^{1,2}$ (D) Rodaina Omar ${ }^{2} \cdot$ Josepha Koehne ${ }^{2}$ (D) Georges Limbert ${ }^{1,3}$ (D) Neil H. Davies ${ }^{2}$ (I) \\ Deon Bezuidenhout ${ }^{2}$ (I) . Thomas Franz ${ }^{1,3}$
}

Received: 6 December 2019 / Accepted: 15 April 2020 / Published online: 24 April 2020

C) Springer Nature Switzerland AG 2020

\begin{abstract}
Consistent mechanical performance from implantation through healing and scaffold degradation is highly desired for tissue-regenerative scaffolds, e.g. when used for vascular grafts. The aim of this study was the paired in vivo mechanical assessment of biostable and fast degrading electrospun polyester-urethane scaffolds to isolate the effects of material degradation and tissue formation after implantation. Biostable and degradable polyester-urethane scaffolds with substantial fibre alignment were manufactured by electrospinning. Scaffold samples were implanted paired in subcutaneous position in rats for 7, 14 and 28 days. Morphology, mechanical properties and tissue ingrowth of the scaffolds were assessed before implantation and after retrieval. Tissue ingrowth after 28 days was $83 \pm 10 \%$ in the biostable scaffold and $77 \pm 4 \%$ in the degradable scaffold. For the biostable scaffold, the elastic modulus at $12 \%$ strain increased significantly between 7 and 14 days and decreased significantly thereafter in fibre but not in cross-fibre direction. The degradable scaffold exhibited a significant increase in the elastic modulus at $12 \%$ strain from 7 to 14 days after which it did not decrease but remained at the same magnitude, both in fibre and in cross-fibre direction. Considering that the degradable scaffold loses its material strength predominantly during the first 14 days of hydrolytic degradation (as observed in our previous in vitro study), the consistency of the elastic modulus of the degradable scaffold after 14 days is an indication that the regenerated tissue construct retains its mechanical properties.
\end{abstract}

Keywords Electrospinning $\cdot$ Elastic modulus $\cdot$ Mechanical properties $\cdot$ Soft tissue regeneration $\cdot$ Degradation

\section{Introduction}

Regenerative medicine has emerged as one of the most dynamic drivers in the development of advanced engineered biomaterial solutions for tissue engineering applications [1, 2]. One crucial element in regenerative medicine are scaffolds that facilitate and guide the regeneration of biological tissues according to the biophysical requirements of the specific application.
The ideal conduit for arterial replacement or bypass remains autologous grafts, i.e. the patient's own artery or vein. Autologous grafts are, however, often unavailable due to either disease or previous use for bypass grafting [3-7]. Whereas currently available vascular prostheses made from polyethylene terephthalate (PET) such as Dacron ${ }^{\oplus}$, and expanded polytetrafluoroethylene (ePTFE) perform well as large-calibre replacements, their longterm patency is discouraging in small to medium graft

Thomas Franz, thomas.franz@uct.ac.za|'Division of Biomedical Engineering, Department of Human Biology, University of Cape Town, Observatory, South Africa. ${ }^{2}$ Cardiovascular Research Unit, Chris Barnard Division of Cardiothoracic Surgery, University of Cape Town, Observatory, South Africa. ${ }^{3}$ National Centre for Advanced Tribology and Bioengineering Science Research Group, Department of Mechanical Engineering Sciences, Faculty of Engineering and Physical Sciences, University of Southampton, Southampton, UK. 
( $<7 \mathrm{~mm}$ ) applications $[3,4,8]$. This limitation is mainly a result of a poor healing process with surface thrombogenicity due to the lack of endothelial cells, as well as anastomotic intimal hyperplasia [5, 9]. Although attempts have been made to improve these grafts by means of various coatings, the results are not conclusive [5, 10-12].

Tissue engineering and regeneration has provided a promising avenue for the development of vascular grafts. The ideal scaffold facilitates tissue regeneration such that the new tissue constructs mimics biologically and mechanically the healthy vascular tissue [2]. For small-tomedium diameter tissue engineered or tissue regenerative vascular grafts, a key factor for long term success is porosity [8]. The complete healing of the porous vascular graft implies interconnected pores to permit transmural tissue ingrowth $[8,13,14]$.

Several approaches have been used to obtain porous polymeric scaffolds for vascular grafts, including particulate leaching [14-16], thermally induced phase separation $[17,18]$. Another method of introducing porosity in vascular scaffolds is electrospinning [19-24]. Here, the adjustment of process parameters allows controlling the degree of fibre alignment in the resulting polymeric network [25, 26]. Fibre alignment strongly determines the mechanical properties of the scaffold [9]. Random fibre alignment leads to mechanical isotropy of the scaffold, which exhibits similar properties in different directions. In contrast, the predominant alignment of fibres in one direction introduces mechanical anisotropy [26].

Electro-spun scaffolds with a high degree of fibre alignment exhibit the highest elastic modulus, i.e. stiffness, in direction of the predominant fibre alignment and the lowest elastic modulus perpendicular to the fibre alignment. Mechanical anisotropy can offer a useful tool to tailor the structural properties of the scaffold but also adds complexity to the design process. The latter needs to be addressed adequately, in particular for biodegradable scaffolds and considering that tissue regenerating in the scaffold will contribute to structural and mechanical properties of the regenerating tissue construct.

Scaffold degradation and tissue incorporation are transient processes, and gradual change of the mechanical properties of the scaffold-tissue construct is expected until degradation and tissue ingrowth are complete. Biomechanical properties of scaffolds were predominantly obtained prior to tissue culturing or implantation [19, 22, 27-30] whereas the changes in mechanical properties due to in situ tissue ingrowth after implantation in fast-degrading scaffolds have received very little attention.

In previous studies, we separately quantified the effect of in vitro degradation [31] and in situ tissue ingrowth in a biostable scaffold [32] on the scaffolds' mechanical properties. The present study aimed at investigating the combined effects of concurrent in situ tissue ingrowth and scaffold degradation on the mechanical properties of a fast-degrading electrospun polyester-urethane scaffold. Matched implants of the polyester-urethane scaffold with a fast-degrading and a non-degrading formulation, respectively, served as internal controls.

\section{Materials and methods}

\subsection{Material}

DegraPol $^{\circledR}$ (ab medica S.p.A, Cerro Maggiore, MI, Italy), a biodegradable polyester-urethane that consists of poly( $\varepsilon$-caprolactone-co-glycolide)-diol soft segments and poly(3-(R-hydroxybutyrate)-co-( $\varepsilon$-caprolactone))-diol hard segments was used. Both polymer segments are biodegradable and their degradation products are non-toxic [33]. The mechanical properties of the polymer can be modulated by adjusting the ratio of the hard and soft segments. Changing the ratio of $\varepsilon$-caprolactone to glycolide affects the degradation characteristics. DegraPol ${ }^{\circledR}$ DP0 and DP30 have $\varepsilon$-caprolactone-to-glycolide ratio of 100:0 and 70:30 respectively, and both have a hard-to-soft segment ratio of 40:60 (unpublished data).

\subsection{Electro-spinning and sample preparation}

DegraPol ${ }^{\circledast}$ DP0 and DP30 were each dissolved in chloroform at room temperature with subsequent sonication in distilled water at $37^{\circ} \mathrm{C}$ for $90 \mathrm{~min}$ to obtain polymer solutions of $24 \%$ by weight concentration. The DegraPol ${ }^{\circledR}$ solution was electro-spun from a hypodermic needle (SE400B syringe pump, Fresenius, Bad Homburg, Germany) onto a rotating and bi-directionally translating tubular target (hypodermic tubing, Small Parts, Loganport, IN, USA) using a custom-made rig. The spinning parameters were: solution flow rate of $4.8 \mathrm{~mL} / \mathrm{h}$, target outer diameter of $25 \mathrm{~mm}$, target rotating speed of $9600 \mathrm{rpm}$, target translational speed of $2.6 \mathrm{~mm} / \mathrm{min}$, potential difference of $15 \mathrm{kV}$, and source-target distance of $250 \mathrm{~mm}$. After completion of the spinning process, the electro-spun structure on the target hypotube was submersed in ethanol for $5 \mathrm{~min}$, removed from the mandrel and dried under vacuum (Townson \& Mercer Ltd, Stretford, England; room temperature, $90 \mathrm{~min}$ ) and trimmed on either end to discard regions with decreasing wall thickness. Tubular scaffolds were cut into rectangular samples with the longer edge aligned with either the circumferential (C) or axial (A) direction of the tube. Samples underwent standard ethylene oxide sterilisation $\left(55^{\circ} \mathrm{C}, 60 \%\right.$ relative humidity, $\left.12 \mathrm{~h}\right)$ and were subsequently placed in vacuum for $6 \mathrm{~h}$ to allow removal of ethylene oxide. 


\subsection{Physical characterisation of scaffold before implantation}

Physical characterisation included microscopic analysis of fibre diameter and alignment, measurement of scaffold wall thickness and porosity as described previously [32].

\subsubsection{Fibre diameter and alignment}

Scanning electron microscope (SEM) images were obtained (Nova NanoSEM 230, FEl, Hillsboro, OR, US) of samples after sputter-coating with gold (Polaron SC7640, Quorum Technologies, East Grinstead, UK). The fibre diameter was measured on $\times 750$ SEM micrographs with Scion Image (Scion Corporation, Frederick, USA) $(n=3$ samples; 4 images per sample, i.e. one image from two different locations of each sample surface; ten measurements per image). Fibre alignment was quantified on $\times 100$ SEM images using Fiji [34], by means of Fourier component analysis with the Directionality plug-in (written by JeanYves Tinevez) as described by Woolley et al. [35]. The analysis provides a dispersion factor as a measure of alignment of the fibres with smaller dispersion values indicating higher degree of alignment.

\subsubsection{Sample dimensions}

Width, length and thickness of scaffold samples were measured on macroscopic images obtained with a Leica DFC280 stereo microscope using Leica IM500 imaging software (Leica Microsystems GmbH, Wetzlar, Germany).

\subsubsection{Scaffold porosity}

Scaffold porosity, P, was determined by hydrostatic weighing typically employed for density determination. The porosity of fibrous networks is described as volumetric ratio

$P=\frac{V_{\text {pores }}}{V_{\text {total }}}=\frac{V_{\text {pores }}}{V_{\text {pores }}+V_{\text {fibres }}}$,

and when expressing volumes as masses in the form of

$P=\frac{m_{\text {eth.pores }}}{m_{\text {eth.pores }}+m_{\text {eth.fibres }}}$.

Introducing measurable quantities $m_{\text {wet }}, m_{d r y}$ and $m_{\text {submerged }}$ provides

$$
\begin{aligned}
P & =\frac{m_{\text {wet }}-m_{\text {dry }}}{m_{\text {wet }}-m_{\text {submerged }}} \\
& =\frac{\left(m_{\text {fibres }}+m_{\text {eth.pores }}\right)-\left(m_{\text {fibres }}\right)}{\left(m_{\text {fibres }}+m_{\text {eth.pores }}\right)-\left(m_{\text {fibres }}-m_{\text {eth.fibres }}\right)} \\
& =\frac{m_{\text {eth.pores }}}{m_{\text {eth.pores }}+m_{\text {eth.fibres }}}
\end{aligned}
$$

with $m_{d r y}$ as the mass of the dry scaffold, $m_{\text {submerged }}$ as the mass of the scaffold submerged in ethanol, and $m_{\text {wet }}$ as the scaffold mass after removal from the ethanol while ethanol is retained in the pores. The porosity was measured with $\mathrm{n}=1$ per spun scaffold.

\subsection{Molecular weight}

Weight-average molar weight, $M_{W^{\prime}}$ during degradation was determined by gel permeation chromatography (GPC) using tuneable absorbance detector (Waters 486, set to $260 \mathrm{~nm}$ ), high-performance liquid chromatography pump (Waters 510), differential refractometer (Waters 410) and auto sampler (Spectra Series AS100, Thermo Separations). Five columns (Styragels HR1 through HR6, Waters) and a pre-column filter were used at $30^{\circ} \mathrm{C}$. Polystyrene standards were used for calibration. Samples were dissolved in tetrahydrofuran ( $1 \mathrm{mg} / \mathrm{ml}, 37^{\circ} \mathrm{C}$, sonication for $20 \mathrm{~min}$ ). A sample volume of $180 \mu \mathrm{l}$ was injected with a flow rate of $1.06 \mathrm{ml} / \mathrm{min}$.

\subsection{Study design}

This study used a subcutaneous rat model with implant durations of 7,14 and 28 days and $n=10$ animals per each time point. Each animal received six implants, namely thee biostable DPO scaffold samples and three biodegradable DP30 scaffold samples.

\subsection{Implantation procedure}

All animal experiments were authorised by the Faculty of Health Sciences Research Ethics Committee of the University of Cape Town and were performed in accordance with the National Institutes of Health (NIH, Bethesda, MD) guidelines.

Male Wistar albino rats with body mass 200-250 $\mathrm{g}$ were used. Anaesthesia was induced by placing the animal in an inhalation chamber with an air flow of $5 \%$ isoflurane for $5 \mathrm{~min}$. The animals were shaved and sterilized with iodine in the area of the incision. Anaesthesia was maintained by nose cone delivery of $1.5 \%$ isoflurane at an oxygen output of $1.5 \mathrm{~L} / \mathrm{min}$ at $1 \mathrm{bar}$ and $21^{\circ} \mathrm{C}$. The body temperature of the animals was maintained throughout the surgical procedure by placing the animal on a custom-made heating pad at $37^{\circ} \mathrm{C}$. 
Six longitudinal incisions of $1 \mathrm{~cm}$ (three on either side of the dorsal midline) were made and subcutaneous pockets of $2 \mathrm{~cm}$ depth bluntly dissected. Scaffold samples were placed within the pockets and incisions closed with silk 4/0 (Ethicon Inc, Somerville, NJ) interrupted sutures in a subcuticular fashion.

\subsection{Implant retrieval}

Anaesthesia was induced by placing the animal in an inhalation chamber with an air flow of 5\% isoflurane for $5 \mathrm{~min}$. Rats were euthanized by inhalation of $5 \%$ halothane in air followed by a cardiac injection of $1 \mathrm{ml}$ saturated $\mathrm{KCl}$ solution. The samples with surrounding tissue were excised. Samples for mechanical testing were submerged in phosphate
Fig. 1 SEM micrographs of electrospun DegraPol ${ }^{\oplus}$ DP0 and DP30 scaffold at magnification of $100 \times$ (top), $750 \times$ (middle) and 3500× (bottom)
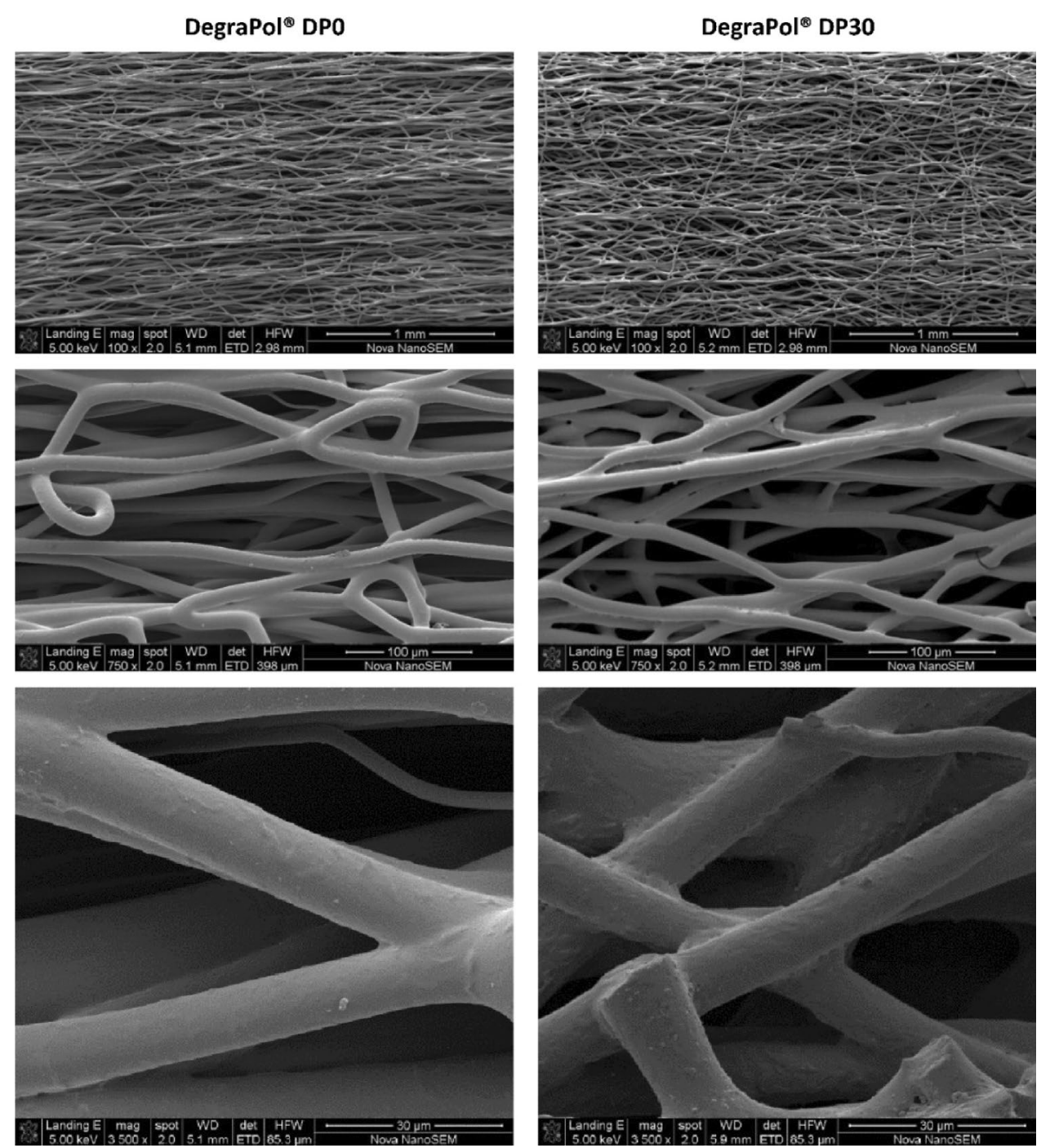

Table 1 Morphometric properties of the electrospun scaffolds

\begin{tabular}{lclrl}
\hline Parameter & $\mathrm{n}$ & DegraPol $^{\circledR}$ DP0 & $\mathrm{n}$ & DegraPol $^{\circledR}$ DP30 \\
\hline Porosity & 7 & $74.0 \pm 3.2 \%$ & 6 & $77.0 \pm 2.7 \%$ \\
Fibre diameter & 3 & $13.0 \pm 2.2 \mu \mathrm{m}$ & 3 & $12.7 \pm 4.1 \mu \mathrm{m}$ \\
Dispersion (goodness) & 6 & $9.6^{\circ} \pm 2.0^{\circ}(0.97 \pm 0.01)$ & 6 & $17.8^{\circ} \pm 4.6^{\circ}(0.98 \pm 0.01)$ \\
Width & 70 & $8.6 \pm 0.5 \mathrm{~mm}$ & 68 & $8.1 \pm 0.5 \mathrm{~mm}$ \\
Thickness & 70 & $1.2 \pm 0.2 \mathrm{~mm}$ & 68 & $1.2 \pm 0.2 \mathrm{~mm}$ \\
Length & 70 & $11.1 \pm 1.6 \mathrm{~mm}$ & 68 & $11.1 \pm 1.5 \mathrm{~mm}$ \\
\hline
\end{tabular}


buffered saline (PBS) solution and stored at $4{ }^{\circ} \mathrm{C}$. Samples for histological analysis underwent tissue fixation in $10 \%$ formalin (Sigma Aldrich, Steinheim, Germany) for $48 \mathrm{~h}$ and transferred into $70 \%$ ethanol solution for storage.

\subsection{Mechanical testing}

Prior to testing, the thickness, length and width of retrieved samples were determined with a calliper. Tensile testing was performed within $12 \mathrm{~h}$ of implant retrieval with samples submerged in PBS at $37^{\circ} \mathrm{C}$ (Instron 5544, $10 \mathrm{~N}$ load cell; Instron, Norwood, USA). Samples were fixed using custom-made clamps resulting in a gauge length of approximately $10 \mathrm{~mm}$. The direction of tensile load represented either circumferential (C samples) or axial direction (A samples) of the original tubular scaffold.

Pre-implant samples ( $T=0$ days) underwent a loading protocol comprising either (1) one initial extension to $12 \%$ strain, five cycles between $12 \%$ and $8 \%$ strain, and a final extension to failure or maximum force of $7.4 \mathrm{~N}$ (all at strain rate of $9.6 \% / \mathrm{min}$ ); or (2) one single extension to $16 \%$ strain at $9.6 \% / \mathrm{min}$. Retrieved implant samples were not subjected to loading cycling but underwent one single extension only (to $16 \%$ strain at $9.6 \% / \mathrm{min}$ ) to avoid inducing structural damage in the degraded samples at the latter stages of the study. Stress-strain data obtained for pre-implant scaffold samples with and without load-cycling was used to derive a scaling function $S_{C}(\varepsilon)=\sigma_{\text {Cycled }}(\varepsilon) / \sigma_{\text {Noncycled }}(\varepsilon)$ that quantifies the mechanical effect of the load-cycling. Stress-strain data obtained without load cycling on retrieved scaffold samples were adjusted using $\mathrm{S}_{\mathrm{C}}$ for each test and average data calculated. Characteristic mechanical measures were derived from these data, namely stress $\sigma_{12 \%}$ at $12 \%$ strain and $\sigma_{16 \%}$ at $16 \%$ strain, and elastic modulus $\mathrm{E}_{6 \%}$ at $6 \%$ strain and $\mathrm{E}_{12 \%}$ at $12 \%$ strain. (Note: Stress and strain always refers to nominal stress and Cauchy strain, respectively.)

\subsection{Histology, light microscopy and assessment of tissue ingrowth}

Fixed samples underwent tissue processing and paraffin embedding. Sections of $3 \mu \mathrm{m}$ thickness were prepared from mid sample regions and stained with haematoxylin and eosin (H\&E) for nuclei and cytoplasm. Microscopic images were acquired with a Nikon Eclipse 90i microscope with digital camera DXM-1200C (Nikon Corporation, Tokyo, Japan).

Tissue ingrowth was quantified by morphometric image analysis classifying areas as open space or tissue (VIS Visiopharm Integrator System, Visiopharm, Hørsholm, Denmark). A region of interest (ROI) in the image was segmented in tissue (nuclei, cytoplasm and extracellular matrix) and open space with an untrained k-means clustering technique. The algorithm classified scaffold fibres as open space since the polymer did not stain. This was corrected by adjusting for scaffold porosity.

\subsection{Statistical analysis}

For quantitative data, one-way ANOVA was performed when more than two groups were compared, using Tukey HSD post hoc analysis with $p<0.05$ indicating statistical significance. Data are provided as mean values \pm standard deviation.

\section{Results}

SEM micrographs of the electrospun DegraPol ${ }^{\oplus}$ DP0 and DP30 scaffolds are shown in Fig. 1. Fibre diameter $(13.0 \pm 2.2 \mu \mathrm{m}$ vs $12.7 \pm 4.1 \mu \mathrm{m})$ and scaffold porosity $(74.0 \pm 3.2 \%$ vs $77.0 \pm 2.7 \%)$ agreed reasonably well between DP0 and DP30. The fibre dispersion was lower (i.e. fibre alignment was higher) in DPO scaffolds $\left(9.6^{\circ} \pm 2.0^{\circ}\right)$ compared to DP30 scaffolds $\left(17.8^{\circ} \pm 4.6^{\circ}, p<0.05\right)$. Scaffolds of both materials exhibited some degree of fibre merging (Fig. 1 bottom row). Morphological scaffold data and dimensions of the scaffold samples for implantation are summarised in Table 1.

Weight-averaged molar weight of DegraPol ${ }^{\circledast}$ DP30 decreased significantly from $77.6 \pm 5.7 \mathrm{kDa}$ at $\mathrm{T}=0$ days to $26.1 \pm 6.7 \mathrm{kDa}$ at $\mathrm{T}=28$ days, see Fig. 2 . Approximately half of this decrease occurred within the first 7 days (51\%), whereas the decrease continued more gradually ( $T=7$ to 14 days: $19 \%, T=14$ to 21 days: $16 \%, T=21$ to 28 days: 14\%). Biostable DegraPol ${ }^{\circledR}$ DPO was analysed at $\mathrm{T}=0$ and 28 days only $(n=1)$ and did not exhibit a change in $M_{W}$.

Tissue ingrowth after 28 days was slightly higher, although not statistically significant, in DegraPol ${ }^{\circledR}$ DPO

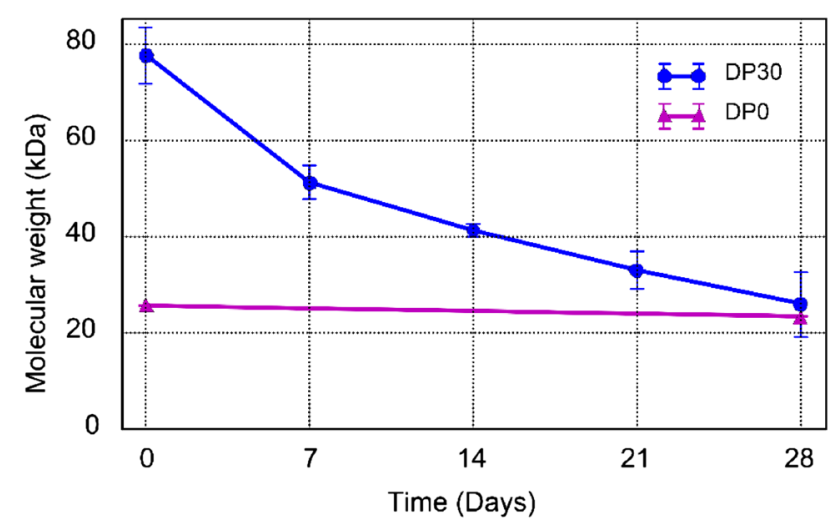

Fig. 2 Molecular weight of DegraPol ${ }^{\oplus}$ DP0 and DP30 samples submerged in PBS versus exposure time up to 28 days 
scaffolds $(83 \pm 10 \%)$ compared to DegraPol ${ }^{\circledR}$ DP30 scaffolds (77 $\pm 4 \%)$. The progress of tissue ingrowth throughout the study is illustrated in representative micrographs of $\mathrm{H} \& \mathrm{E}$ sections of the scaffolds and quantified in Fig. 3.

Figure 4a shows stress-strain data for axial and circumferential directions of pre-implant scaffold samples with and without load cycling. The resulting axial and circumferential stress scaling functions $S_{C}(\varepsilon)$ are illustrated in Fig. 4b. These functions quantify the impact of the load cycling for strains up to $16 \%$. Disregarding data for strain below 2\% (due to low signal-to-noise ratio), it was observed for axial DegraPol ${ }^{\circledR}$ DP0 scaffold samples that load cycling reduced the stress, $\sigma_{\text {Cycled }}$, to $0.43 \%$ of the stress of non-cycled scaffolds, $\sigma_{\text {Noncycled }}$ for strain, $\varepsilon$, between $2 \%$ and $12 \%$. For $\varepsilon \geq 12 \%$, load cycling decreased the stress to $\sigma_{\text {Cycled }}=0.33 \sigma_{\text {Noncycled }}$, indicating
Fig. 3 Histology micrographs of $\mathrm{H} \& \mathrm{E}$ sections in mid region of DegraPol ${ }^{\circledR}$ DP0 and DP30 scaffold samples and extent of tissue ingrowth after 7, 14 and 28 days of implantation
Time

DegraPol® DP0

Ingrowth

7 Days

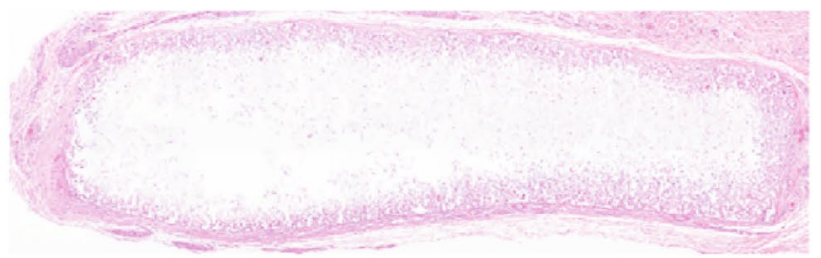

$31 \pm 5 \%$

14 Days

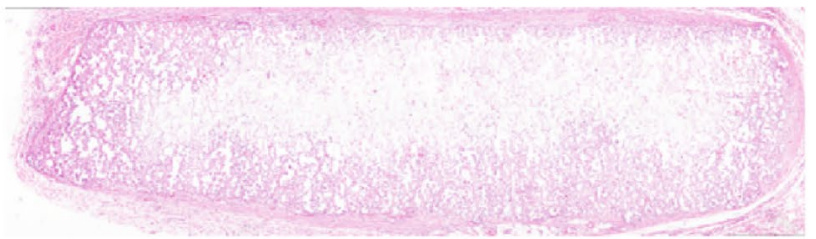

$58 \pm 14 \%$

28 Days

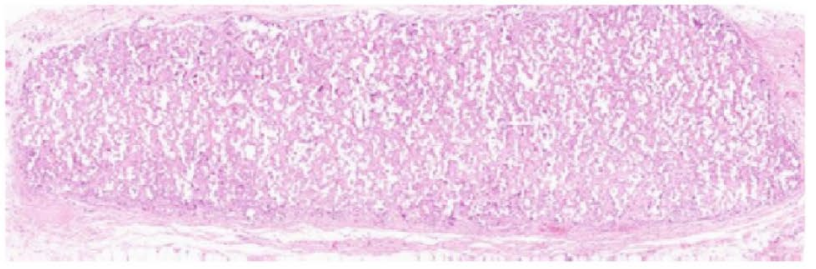

$83 \pm 10 \%$
7 Days

14 Days

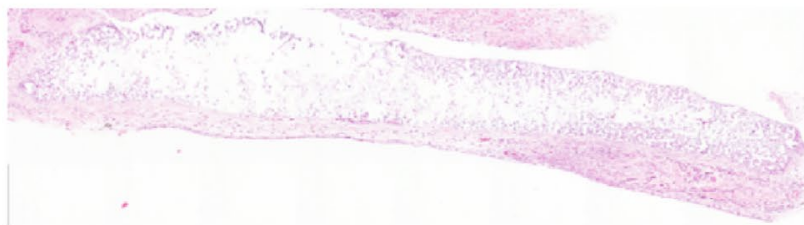

$29 \pm 11 \%$

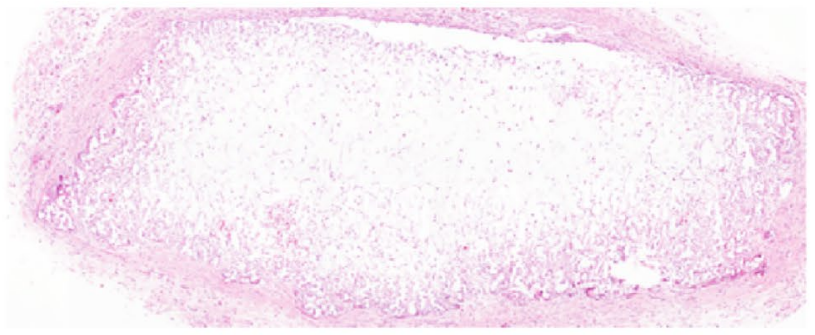

$55 \pm 19 \%$

28 Days

$77 \pm 4 \%$

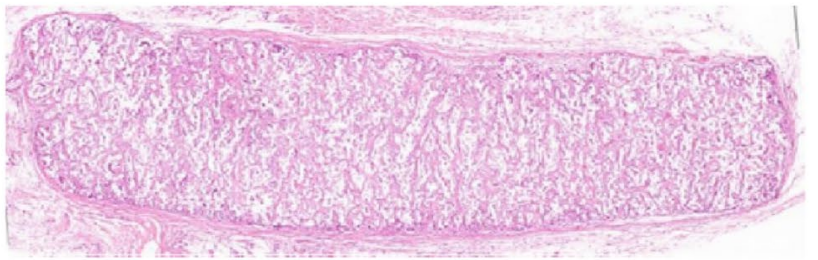


further weakening of the scaffold. For circumferential DegraPol ${ }^{\circledast}$ DP0 samples, $\sigma_{\text {Cycled }}$ gradually increased from $0.20 \sigma_{\text {Noncycled }}$ at $\varepsilon=2 \%$ to $0.59 \sigma_{\text {Noncycled }}$ at $\varepsilon=12 \%$ strain, and decreased to $047 \sigma_{\text {Noncycled }}$ at $\varepsilon=16 \%$. For DegraPol ${ }^{\circledR}$ DP30 scaffold, load cycling resulted in stress between $\sigma_{\text {Cycled }}=0.80 \sigma_{\text {Noncycled }}$ at $\varepsilon=2 \%$ and $\sigma_{\text {Cycled }}=0.98$ $\sigma_{\text {Noncycled }}$ at $\varepsilon=12 \%$ and $16 \%$ in axial scaffold direction, compared to $\sigma_{\text {Cycled }}=0.26 \sigma_{\text {Noncycled }}$ at $\varepsilon=2 \%, 0.93$ $\sigma_{\text {Noncycled }}$ at $\varepsilon=12 \%$, and $0.97 \sigma_{\text {Noncycled }}$ at $\varepsilon=16 \%$ in circumferential scaffold direction.

Figure 5 illustrates stress-strain data obtained without load cycling as measured for DegraPol ${ }^{\circledR}$ DP0 and DP30 scaffolds in circumferential and axial directions at the various time points of the study. Stress-strain data after incorporation of the effect of load cycling using the stress scaling function $S_{C}(\varepsilon)$ are provided in Fig. 6 ; the mechanical characteristics $\sigma_{12 \%}, \sigma_{16 \%}, \mathrm{E}_{6 \%}$ and $\mathrm{E}_{12 \%}$ are shown in Fig. 7. The changes of stress and elastic modulus from 0 to 14 and from 14 to 28 days are summarized in Table 2 .

\section{Discussion}

The current study facilitated the paired in vivo assessment of the mechanics of biostable and degradable electrospun scaffolds based on the same polyester-urethane formulation to isolate the effects of material degradation and tissue formation after implantation. Biostable and biodegradable polyester-urethane scaffolds were implanted in the same animal.

The mechanical properties of biostable DegraPol ${ }^{\otimes}$ DP0 and degradable DegraPol ${ }^{\circledR}$ DP30 were found to be in the same range, although different responses were observed over implantation time. For DegraPol ${ }^{\oplus} \mathrm{DPO}$, circumferential data, but not axial, showed a significant increase from $T=7$ to 14 days, and a significant decrease from $T=14$ to 28 days in all characteristic measures, namely stress at $12 \%$ and $16 \%$ strain, and elastic modulus at $6 \%$ and $12 \%$ strain (Table 2). DegraPol ${ }^{\circledR}$ DP30 scaffolds exhibited a significant increase in stiffness in vivo. Whereas $\mathrm{E}_{6 \%}$ did not change, $E_{12 \%}$ increased between $\mathrm{T}=7$ to 14 days by $50 \%(p<0.05)$ for circumferential samples and by $213 \%$ for axial samples. This increase in elastic modulus was not reflected in the
Fig. 4 a Stress versus strain curves for circumferential and axial direction of DegraPol ${ }^{\oplus}$ DP0 and DP30 scaffolds before implantation ( $T=0$ day) for tensile loading protocol without and with load cycling; $\mathbf{b}$ Stress scaling factor $\mathrm{S}_{\mathrm{C}}=\sigma_{\text {Cycled }}$ $\sigma_{\text {Noncycled }}$ versus strain, obtained from data shown in a, representing the effect of load cycling on stress-strain behaviour of DegraPol ${ }^{\circledR}$ DP0 and DP30. Data for strains below $2 \%$ were not considered due to high signal-to-noise ratio of force data based on low force magnitudes

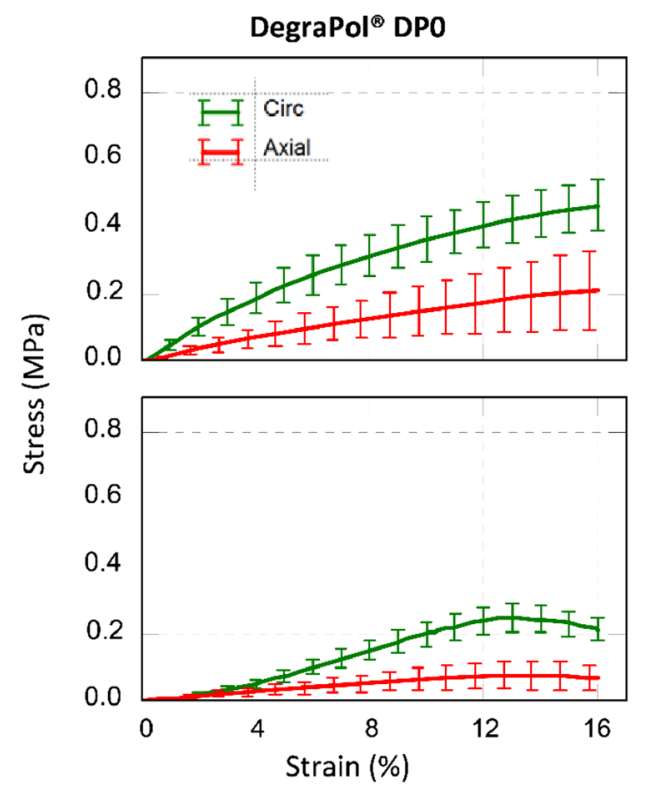

DegraPol ${ }^{\circledR}$ DPO

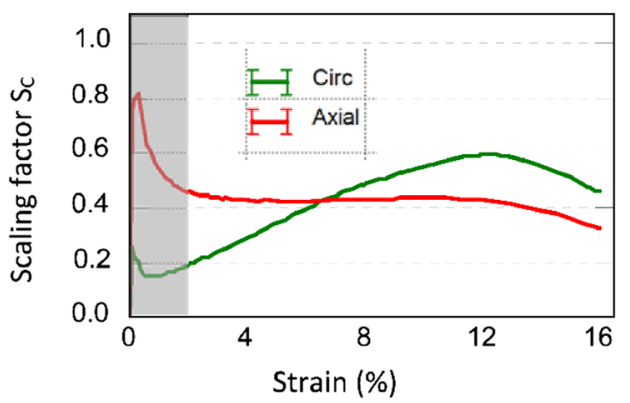

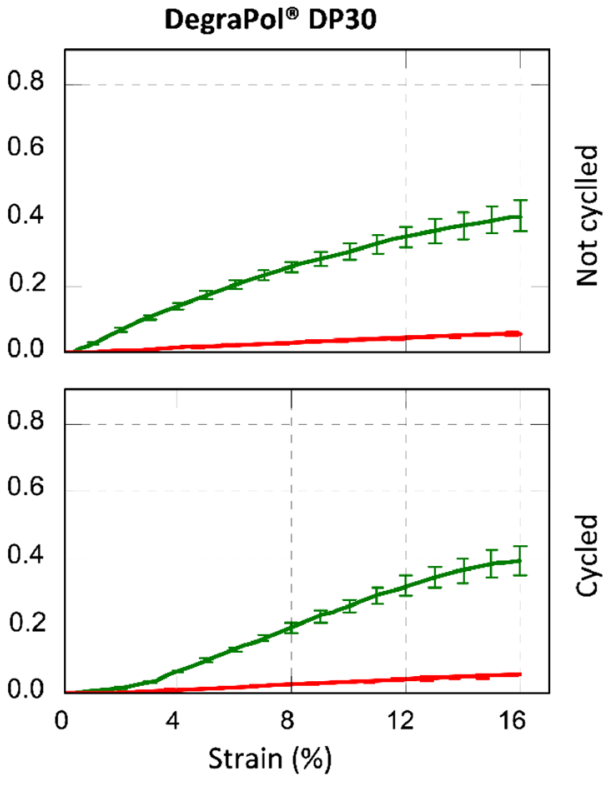

DegraPol ${ }^{\circledR}$ DP30

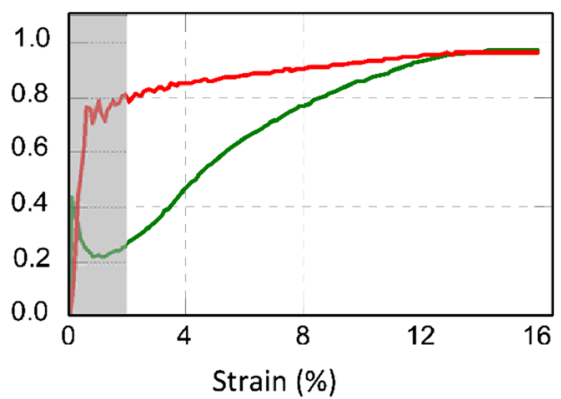

SN Applied Sciences 
stress of circumferential samples but was for axial samples. Stress at $16 \%$ remained constant between $\mathrm{T}=0$ and 7 days but increased by $296 \%$ at $\mathrm{T}=14$ days $(p<0.05)$ and remained at that level at $T=28$ days. The increase in elastic modulus after $T=7$ days was linked to tissue ingrowth. Although there was approximately $30 \%$ ingrowth by 7 days, it was not yet fully interconnected throughout the scaffold, and thus did not contribute much to the overall mechanics. As tissue continued to populate the scaffold, regions with neo-tissue interconnected and developed greater structural strength.

Consistent mechanical performance from implantation through healing and scaffold degradation is highly desired for tissue-regenerative scaffolds, e.g. when used for vascular grafts. In the early phase after implantation, the circumferential stiffness in the scaffolds is based predominantly on fibres. As scaffold fibres degrade, the scaffold stiffness will decrease, unless the tissue balances out the difference. The consistency observed in circumferential stiffness of DegraPol ${ }^{\circledR}$ DP30 scaffold was thus of specific importance. Our previous in vitro study showed that the loss in material strength of DegraPol ${ }^{\circledR}$ DP30 predominantly occurred in the first 14 days [31], which correlated with decrease in molecular weight by $T=14$ days. Assuming a similar trend for the scaffold in vivo, it holds that the tissue incorporation was contributing to the overall stiffness and balancing out the loss due to degradation. The stability in circumferential mechanical response contrasts, however, with the results by Teutelink et al. [36] where the grafts not implanted were significantly stiffer than the neo-vessels explanted after 90 days.

DegraPol ${ }^{\circledR}$ DP0 and DP30 scaffolds both featured a substantial degree of fibre alignment. However, DegraPol ${ }^{\circledR}$ DPO scaffolds showed higher fibre alignment than
Fig. 5 Stress versus strain curves for circumferential and axial direction of DegraPol ${ }^{\circledR}$ DP0 and DP30 scaffolds without load cycling before implantation ( 0 day) and after implantation for $\mathrm{T}=7,14$ and 28 days

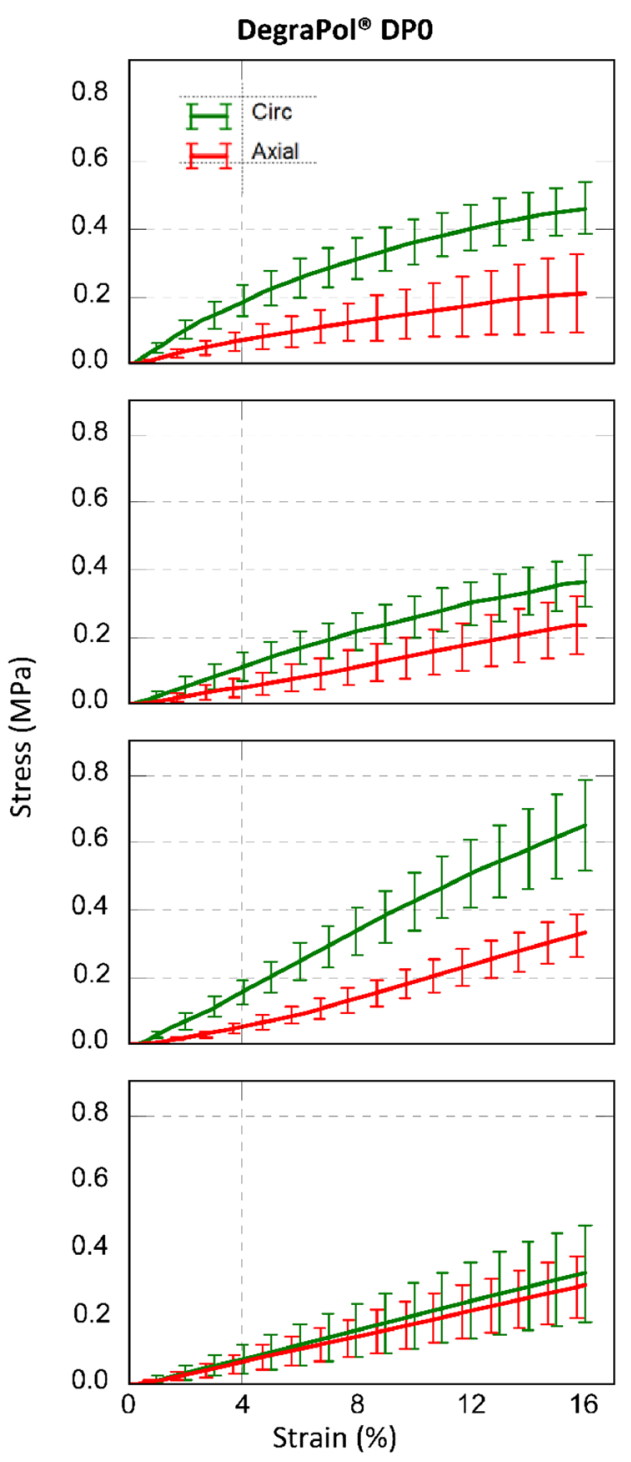

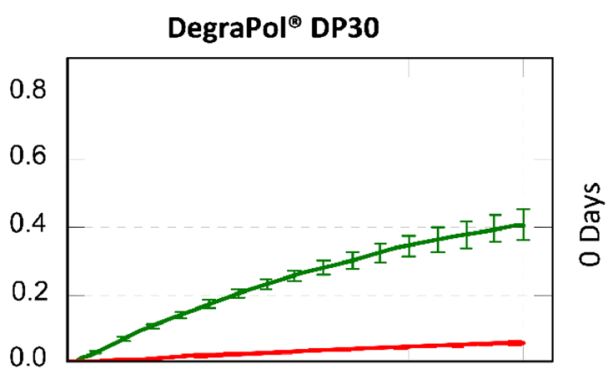
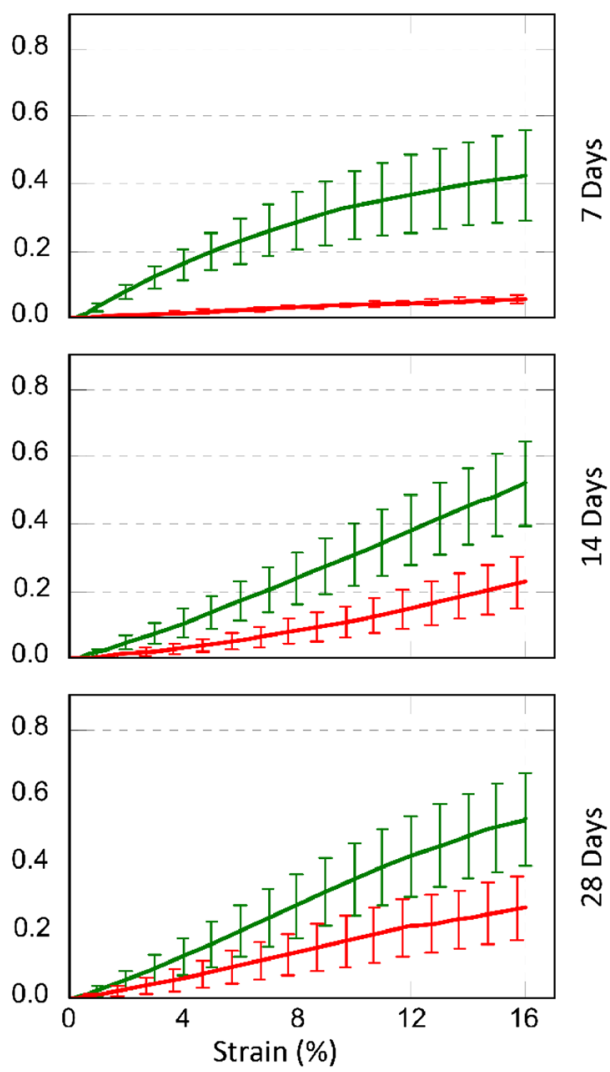
DegraPol ${ }^{\circledast}$ DP30 scaffolds $(p<0.05)$, with high goodness values for the Gaussian fits of the fibre dispersion data in both cases (Table 1).

Tissue ingrowth was similar in DegraPol ${ }^{\circledR}$ DP0 and DP30 scaffolds, although it appeared to be slightly slower in the latter (Fig. 3). Levels of tissue ingrowth increased significantly between all subsequent time points of the study for both DegraPol ${ }^{\oplus}$ DP0 and DP30 scaffolds $(p<0.05)$ except the increase between $\mathrm{T}=14$ and 28 days for DegraPol ${ }^{\otimes}$ DP30.

In order to avoid inducing premature damage in DegraPol$^{\circledR}$ scaffold samples at later time points of the study, load cycling was not included in the protocol for mechanical characterisation. However, the effect of load cycling was characterised for pre-implant scaffolds and applied to scaffolds retrieved at the various time points.
DegraPol ${ }^{\circledast}$ DP0 scaffolds displayed a higher sensitivity to load cycling than the DP30 scaffolds. For DP0 scaffolds, the stress scaling parameter $S_{C}$ ranging between 0.20 and 0.59 indicates that load cycling reduced stress in the scaffold by at least $41 \%$. In addition, the decrease in stress $\sigma_{\text {Noncycled }}$ (Fig. 4a) bottom left panel) and stress scaling parameter $S_{C}$ (Fig. $4 \mathrm{~b}$ left panel) for strain above $12 \%$ indicates damage induced in the DegraPol ${ }^{\circledR}$ DP0 scaffold due to load cycling) both in direction of and transverse to the fibre alignment. For DegraPol ${ }^{\circledR}$ DP30, $\mathrm{S}_{\mathrm{C}}$ ranged between 0.26 and 0.98 across the strain range studied. The DegraPol ${ }^{\circledR}$ DP0 scaffolds showed a more substantial weakening due to precycling when compared to the DegraPol ${ }^{\circledR}$ DP30 scaffolds.

DegraPol ${ }^{\oplus}$ DPO scaffolds were significantly more aligned than DegraPol ${ }^{\circledR}$ DP30, with a mean dispersion angle of less than $10^{\circ}$, compared to $>17^{\circ}$ for DegraPol ${ }^{\circledR}$ DP30.
Fig. 6 Stress adjusted for load cycling versus strain curves for circumferential and axial direction of DegraPol $^{\circledR}$ DP0 and DP30 scaffolds before implantation ( 0 day) and after implantation for $\mathrm{T}=7,14$ and 28 days

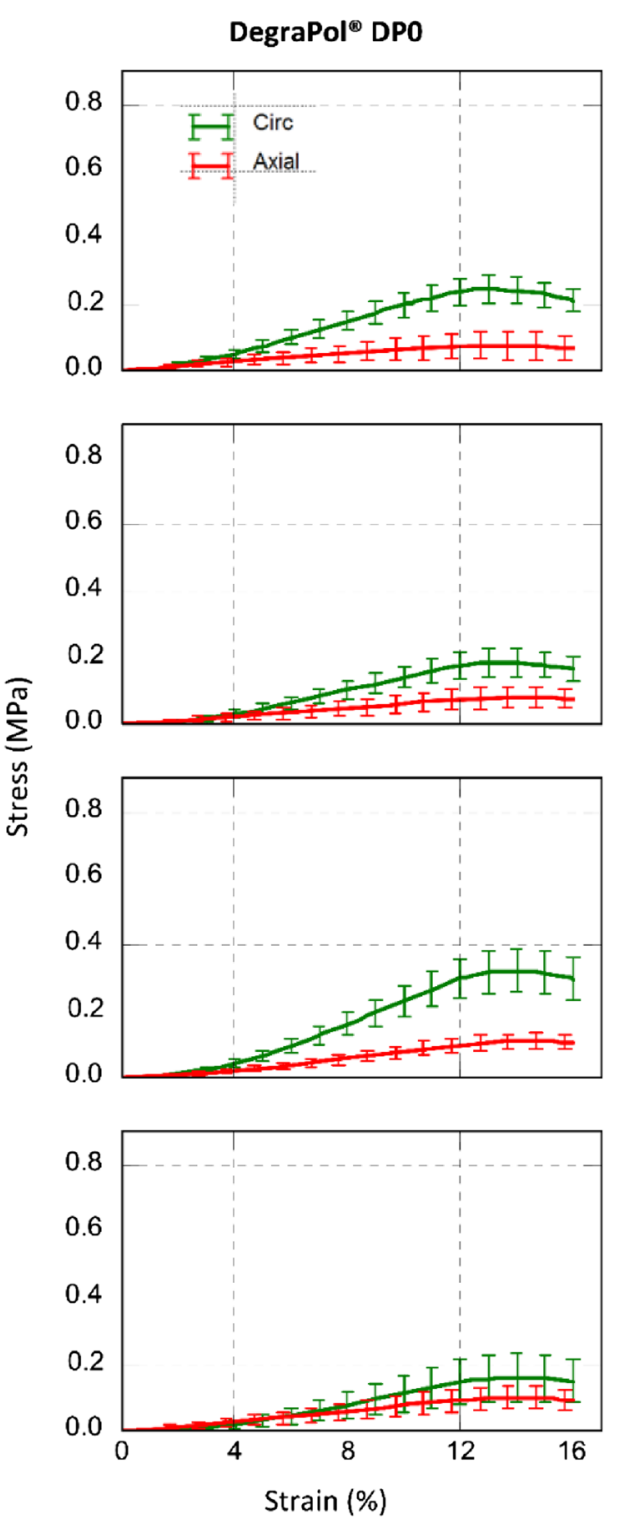

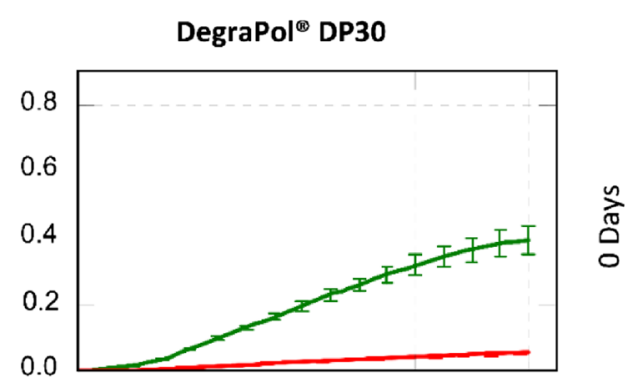

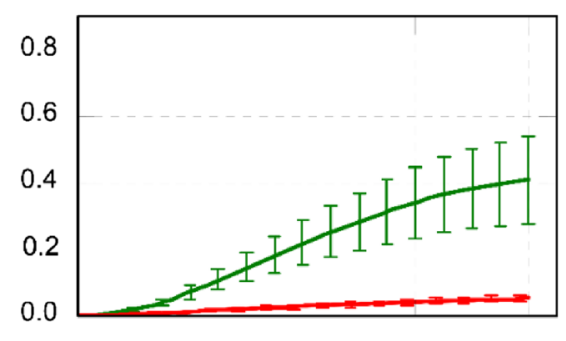

$\frac{n}{\frac{\pi}{0}}$

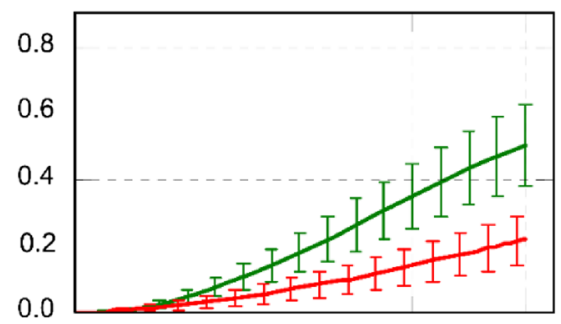

$\frac{\pi}{\pi}$
จ

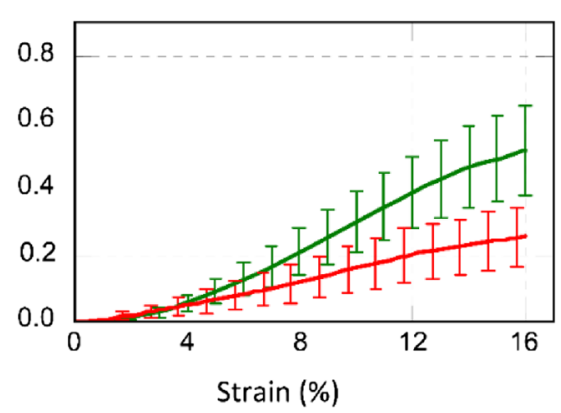

SN Applied Sciences 

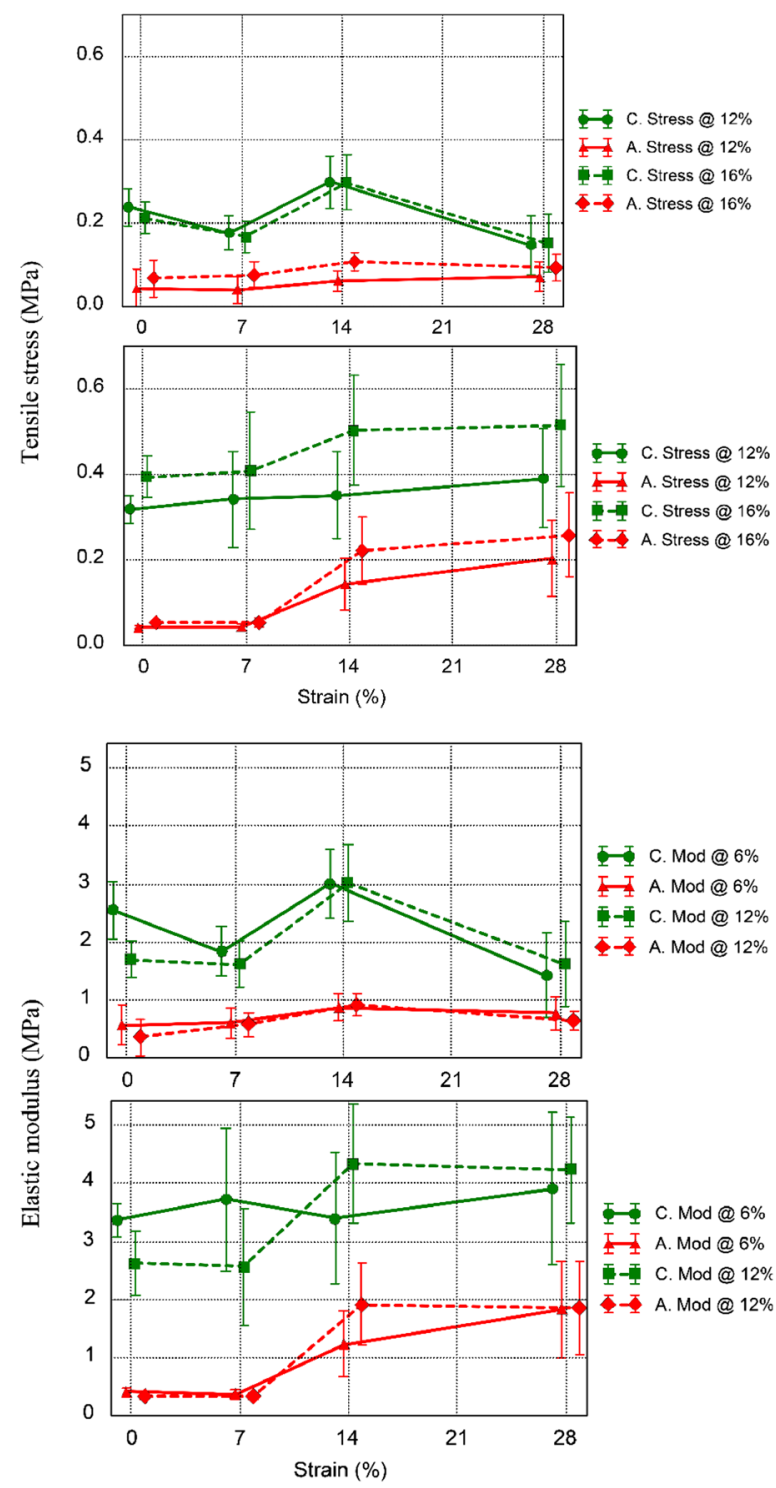

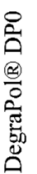

Fig. 7 a Stress at a strain of $12 \%$ and $16 \%$ versus implantation time and $\mathbf{b}$ elastic modulus at a strain of $6 \%$ and $12 \%$ versus implantation time for the circumferential (C) and axial (A) direction of DegraPol $^{\oplus}$ DP0 and DP30 scaffold implants

Table 2 Changes in stress and elastic modulus characteristics from 7 to 14 and 14 to 28 days for DegraPol ${ }^{\oplus}$ DPO ( $p<0.05$ for all values)

\begin{tabular}{lll}
\hline Parameter & $\begin{array}{l}\text { Change from } \mathrm{T}=7 \text { to } \\
14 \text { days }\end{array}$ & $\begin{array}{l}\text { Change from } \\
\mathrm{T}=14 \text { to } \\
28 \text { days }\end{array}$ \\
\hline$\sigma_{12 \%}$ & $+67 \%$ & $-57 \%$ \\
$\sigma_{16 \%}$ & $+78 \%$ & $-49 \%$ \\
$\mathrm{E}_{6 \%}$ & $+63 \%$ & $-52 \%$ \\
$\mathrm{E}_{12 \%}$ & $+87 \%$ & $-46 \%$ \\
\hline
\end{tabular}

DegraPol ${ }^{\circledast}$ DP30 scaffolds also showed more fibre merging than DegraPol ${ }^{\circledR}$ DP0, another possible factor. Lee et al. [37] reported similar behaviour in Pellethane ${ }^{\circledR}$ electrospun meshes. They indicated that a higher degree of fibre merging resulted in better distribution of load compared to an otherwise similar structure with lesser fibre merging. Low degrees of fibre merging led to a structure in which the load was not as readily distributed among fibres, resulting in earlier onset of failure of individual fibres, and consequently the entire mesh. This correlated with the observation that DegraPol ${ }^{\circledR}$ DP30 fibres displayed more merging and higher tolerance to cyclic loading than the DegraPol ${ }^{\otimes}$ DPO scaffolds. In addition, higher alignment led to individual fibres experiencing higher strains at low scaffold strain and thus failing earlier, as the fibres were already straight and thus did not need to first straightened out [38]. Again, the scaffold morphology correlated with tensile test results, with the higher aligned DegraPol ${ }^{\circledast}$ DP0 scaffolds incurring more damage at lower strains, as reflected by the decrease in stress post $12 \%$ strain.

\section{Conclusions}

Considering our previous in vitro observation that the DegraPol ${ }^{\circledast}$ DP30 scaffold loses its material strength predominantly during the first 14 days of hydrolytic degradation, the consistency of the elastic modulus of the degradable scaffold between 14 and 28 days in the current study is an indication that the regenerated tissue construct retains its mechanical properties. The strain stiffening of the tissue constructs with DegraPol ${ }^{\circledR}$ DP30 scaffold from 7 days of implantation onwards (evidenced through the increase of elastic modulus from 6 to $12 \%$ strain) is an additional advantage and mechanical behaviour observed in soft biological tissues such as blood vessels. For the application of the scaffold as tissue regenerative vascular grafts, further research is required to indicate whether similar results will be obtained in the circulatory implant position.

Acknowledgements The authors thank ab medica S.p.A for donating the DegraPol ${ }^{\circledR}$ material for this study. ETH Zurich and the University of Zurich are owners and ab medica S.p.A is exclusive licensee of all Intellectual Property Rights of DegraPol ${ }^{\oplus}$.

Funding This study was supported financially by the National Research Foundation of South Africa and the South African Medical Research Council. HK received a matching dissertation grant from the International Society of Biomechanics. JK acknowledges financial support from the Deutsche Herzstiftung (Jahresstipendium S/08/10). 
Data availability Quantitative data for fibre diameter, fibre alignment, tissue ingrowth and mechanical characterisation are available on ZivaHUB (http://doi.org/10.25375/uct.9892367).

\section{Compliance with ethical standards}

Conflicts of interest The authors declare that they do not have conflicts of interests.

Ethical approval All animal experiments were authorised by the Faculty of Health Sciences Research Ethics Committee of the University of Cape Town and were performed in accordance with the National Institutes of Health (NIH, Bethesda, MD) guidelines.

\section{References}

1. Williams DF (2006) To engineer is to create: the link between engineering and regeneration. Trends Biotechnol 24(1):4-8. https://doi.org/10.1016/j.tibtech.2005.10.006

2. Furth ME, Atala A, Van Dyke ME (2007) Smart biomaterials design for tissue engineering and regenerative medicine. Biomaterials 28(34):5068-5073

3. Ratcliffe A (2000) Tissue engineering of vascular grafts. Matrix Biol 19(4):353-357

4. Chlupac J, Filova E, Bacakova L (2009) Blood vessel replacement: 50 years of development and tissue engineering paradigms in vascular surgery. Physiol Res 58(Suppl 2):S119-S139

5. Berglund JD, Galis ZS (2003) Designer blood vessels and therapeutic revascularization. Br J Pharmacol 140(4):627-636. https ://doi.org/10.1038/sj.bjp.0705457

6. Wang X, Lin P, Yao Q, Chen C (2007) Development of smalldiameter vascular grafts. World J Surg 31(4):682-689. https:// doi.org/10.1007/s00268-006-0731-z

7. Teo W-E, Ramakrishna S (2009) Electrospun nanofibers as a platform for multifunctional, hierarchically organized nanocomposite. Compos Sci Technol 69(11-12):1804-1817. https:// doi.org/10.1016/j.compscitech.2009.04.015

8. Zilla P, Bezuidenhout D, Human P (2007) Prosthetic vascular grafts: wrong models, wrong questions and no healing. Biomaterials 28(34):5009-5027

9. Limbert G, Omar R, Krynauw H, Bezuidenhout D, Franz T (2016) The anisotropic mechanical behaviour of electro-spun biodegradable polymer scaffolds: experimental characterisation and constitutive formulation. J Mech Behav Biomed Mater 53:21-39. https://doi.org/10.1016/j.jmbbm.2015.07.014

10. Ritter EF, Fata MM, Rudner AM, Klitzman B (1998) Heparin bonding increases patency of long microvascular prostheses. Plast Reconstr Surg 101(1):142-146

11. Gosselin C, Vorp DA, Warty V, Severyn DA, Dick EK, Borovetz HS, Greisler HP (1996) ePTFE coating with fibrin glue, FGF-1, and heparin: effect on retention of seeded endothelial cells. J Surg Res 60(2):327-332. https://doi.org/10.1006/jsre.1996.0052

12. Herring $M$, Smith J, Dalsing $M$, Glover J, Compton R, Etchberger K, Zollinger T (1994) Endothelial seeding of polytetrafluoroethylene femoral popliteal bypasses: the failure of low-density seeding to improve patency. J Vasc Surg 20(4):650-655

13. Mooney DJ, Baldwin DF, Suh NP, Vacanti JP, Langer R (1996) Novel approach to fabricate porous sponges of poly(-lactic-coglycolic acid) without the use of organic solvents. Biomaterials 17(14):1417-1422

14. Pennel T, Zilla P, Bezuidenhout D (2013) Differentiating transmural from transanastomotic prosthetic graft endothelialization through an isolation loop-graft model. JVasc Surg 58(4):1053-1061

15. Murphy WL, Dennis RG, Kileny JL, Mooney DJ (2002) Salt fusion: an approach to improve pore interconnectivity within tissue engineering scaffolds. Tissue Eng 8(1):43-52. https://doi. org/10.1089/107632702753503045

16. Jun H-W, West JL (2005) Endothelialization of microporous YIGSR/PEG-modified polyurethaneurea. Tissue Eng 11(78):1133-1140. https://doi.org/10.1089/ten.2005.11.1133

17. Nam YS, Park TG (1999) Biodegradable polymeric microcellular foams by modified thermally induced phase separation method. Biomaterials 20(19):1783-1790. https://doi.org/10.1016/s0142 -9612(99)00073-3

18. Nam YS, Park TG (1999) Porous biodegradable polymeric scaffolds prepared by thermally induced phase separation. J Biomed Mater Res 47(1):8-17. https://doi.org/10.1002/(sici)10974636(199910)47:1\%3c8:aid-jbm2\%3e3.0.co;2-I

19. Bergmeister $H$, Schreiber $C$, Grasl C, Walter I, Plasenzotti $R$, Stoiber M, Bernhard D, Schima H (2013) Healing characteristics of electrospun polyurethane grafts with various porosities. Acta Biomater 9(4):6032-6040. https://doi.org/10.1016/j.actbi 0.2012 .12 .009

20. Hasan A, Memic A, Annabi N, Hossain M, Paul A, Dokmeci MR, Dehghani F, Khademhosseini A (2014) Electrospun scaffolds for tissue engineering of vascular grafts. Acta Biomater 10(1):11-25. https://doi.org/10.1016/j.actbio.2013.08.022

21. Hu J-J, Chao W-C, Lee P-Y, Huang C-H (2012) Construction and characterization of an electrospun tubular scaffold for smalldiameter tissue-engineered vascular grafts: a scaffold membrane approach. J Mech Behav Biomed Mater 13:140-155. https ://doi.org/10.1016/j.jmbbm.2012.04.013

22. McClure MJ, Sell SA, Simpson DG, Walpoth BH, Bowlin GL (2010) A three-layered electrospun matrix to mimic native arterial architecture using polycaprolactone, elastin, and collagen: a preliminary study. Acta Biomater 6(7):2422-2433. https://doi. org/10.1016/j.actbio.2009.12.029

23. Hong JK, Madihally SV (2011) Next generation of electrosprayed fibers for tissue regeneration. Tissue Eng B Rev 17(2):125-142. https://doi.org/10.1089/ten.teb.2010.0552

24. Vatankhah E, Semnani D, Prabhakaran MP, Tadayon M, Razavi S, Ramakrishna S (2014) Artificial neural network for modeling the elastic modulus of electrospun polycaprolactone/gelatin scaffolds. Acta Biomater 10(2):709-721. https://doi.org/10.1016/j. actbio.2013.09.015

25. Wu H, Fan J, Chu C-C, Wu J (2010) Electrospinning of small diameter 3-D nanofibrous tubular scaffolds with controllable nanofiber orientations for vascular grafts. J Mater Sci Mater Med 21(12):3207-3215. https://doi.org/10.1007/s10856-010-4164-8

26. Ayres CE, Bowlin GL, Pizinger R, Taylor LT, Keen CA, Simpson DG (2007) Incremental changes in anisotropy induce incremental changes in the material properties of electrospun scaffolds. Acta Biomater 3(5):651-661

27. de Valence S, Tille JC, Giliberto JP, Mrowczynski W, Gurny R, Walpoth BH, Möller M (2012) Advantages of bilayered vascular grafts for surgical applicability and tissue regeneration. Acta Biomater 8(11):3914-3920. https://doi.org/10.1016/j.actbi 0.2012 .06 .035

28. Zhu M, Wang K, Mei J, Li C, Zhang J, Zheng W, An D, Xiao N, Zhao Q, Kong D, Wang L (2014) Fabrication of highly interconnected porous silk fibroin scaffolds for potential use as vascular grafts. Acta Biomater 10(5):2014-2023. https://doi.org/10.1016/j.actbi 0.2014 .01 .022

29. Henry JJD, Yu J, Wang AJ, Lee R, Fang J, Li S (2017) Engineering the mechanical and biological properties of nanofibrous vascular grafts for in situ vascular tissue engineering. Biofabrication. https://doi.org/10.1088/1758-5090/aa834b 
30. Jirofti N, Mohebbi-Kalhori D, Samimi A, Hadjizadeh A, Kazemzadeh GH (2018) Small-diameter vascular graft using co-electrospun composite PCL/PU nanofibers. Biomed Mater 13(5):055014. https://doi.org/10.1088/1748-605x/aad4b5

31. Krynauw $H$, Bruchmüller $L$, Bezuidenhout $D$, Zilla $P$, Franz $T$ (2011) Degradation-induced changes of mechanical properties of an electro-spun polyester-urethane scaffold for soft tissue regeneration. J Biomed Mater Res B 99B(2):359-368. https://doi. org/10.1002/jbm.b.31907

32. Krynauw H, Buescher J, Koehne J, Verrijt L, Limbert G, Davies $\mathrm{NH}$, Bezuidenhout D, Franz T (2019) Tissue ingrowth markedly reduces mechanical anisotropy and stiffness in fibre direction of highly aligned electrospun polyurethane scaffolds. bioRxiv:779942

33. Milleret V, Simonet $M$, Bittermann AG, Neuenschwander $P$, Hall H (2009) Cyto- and hemocompatibility of a biodegradable 3D-scaffold material designed for medical applications. J Biomed Mater Res B Appl Biomater 91(1):109-121. https://doi. org/10.1002/jbm.b.31379

34. Schindelin J, Arganda-Carreras I, Frise E, Kaynig V, Longair M, Pietzsch T, Preibisch S, Rueden C, Saalfeld S, Schmid B, Tinevez J-Y, White DJ, Hartenstein V, Eliceiri K, Tomancak P, Cardona A
(2012) Fiji: an open-source platform for biological-image analysis. Nat Methods 9(7):676-682

35. Woolley AJ, Desai HA, Steckbeck MA, Patel NK, Otto KJ (2011) In situ characterization of the brain-microdevice interface using device capture histology. J Neurosci Methods 201(1):67-77. https://doi.org/10.1016/j.jneumeth.2011.07.012

36. Teutelink A, van der Laan MJ, Milner R, Blankensteijn JD (2003) Fabric tears as a new cause of type III endoleak with Ancure endograft. J Vasc Surg 38(4):843-846

37. Lee K, Lee B, Kim C, Kim H, Kim K, Nah C (2005) Stress-strain behavior of the electrospun thermoplastic polyurethane elastomer fiber mats. Macromol Res 13(5):441-445. https://doi. org/10.1007/bf03218478

38. Mauck RL, Baker BM, Nerurkar NL, Burdick JA, Li WJ, Tuan RS, Elliott DM (2009) Engineering on the straight and narrow: the mechanics of nanofibrous assemblies for fiber-reinforced tissue regeneration. Tissue Eng B Rev 15(2):171-193. https://doi. org/10.1089/ten.TEB.2008.0652

Publisher's Note Springer Nature remains neutral with regard to jurisdictional claims in published maps and institutional affiliations. 